\title{
Properties of the CdTe/InSb interface studied by optical and surface analytical techniques
}

\author{
Z. C. Feng ${ }^{*}, 1$, S. Y. Hung ${ }^{1}$, and A. T. S. Wee ${ }^{2}$ \\ ${ }^{1}$ Graduate Institute of Electro-Optical Engineering \& Department of Electrical Engineering, \\ National Taiwan University, Taipei, 106-17 Taiwan, ROC \\ ${ }^{2}$ Department of Physics, National University of Singapore, Singapore 119260
}

Received 5 September 2005, revised 2 June 2006, accepted 2 June 2006

Published online 13 July 2006

PACS 68.35.Dv, 68.49.Sf, 78.55.Cr, 79.60.Bm, 81.15.Hi

Indium interdiffusion in MBE-grown CdTe/InSb heterostructures was studied by optical and surface techniques of photoluminescence (PL), X-ray photoelectron spectroscopy (XPS) and secondary ion mass spectrometry (SIMS). A correlation between the two types of investigations is established.

() 2006 WILEY-VCH Verlag GmbH \& Co. KGaA, Weinheim

\section{Introduction}

CdTe is an important material for radiation detectors and photovoltaic (PV) solar cells [1], with various active research activities in recent two decades [1-18]. CdTe/InSb is a significant system because of the very close lattice mismatch $\left(\Delta a / a \sim 5 \times 10^{-4}\right)$ between them $[6,18]$, and therefore, the dissimilar heteroepitaxy between II-VI and III-V compounds, such as CdTe on InSb or InSb on CdTe, is very attractive for applications in optoelectronics $[6,9-11,13,14,16-18]$. We have recently performed a series of investigations on $\mathrm{CdTe} / \mathrm{InSb}$ heterostructures grown by molecular beam epitaxy (MBE) [9, 11, 16-18]. The crystalline perfection and optical/structural properties of CdTe thin films on InSb were greatly affected by the InSb substrate growth temperature, $T_{\mathrm{s}}$, and other growth conditions. It has been reported [ 5 , $6,10,13]$ that In diffuses easily across the $\mathrm{CdTe} / \mathrm{InSb}$ interface and modifies the optical and electronic properties of epitaxial CdTe. In this work, we present a combined study of optical and surface science analyses on the indium interdiffusion in MBE-grown CdTe/InSb heterostructures.

\section{Experimental}

The CdTe films were grown in an MBE machine on (001) InSb substrates which were polished on both sides, ion beam cleaned and subsequently annealed at $\sim 200^{\circ} \mathrm{C}$ prior to MBE growth. Two typical samples involved in this study, No. 248 and 217, were grown at the same growth rate of $0.70 \mu \mathrm{m} / \mathrm{hr}$ to a film thickness of about $1.4 \mu \mathrm{m}$, but at different substrate growth temperatures, $T_{\mathrm{s}}$, of $200{ }^{\circ} \mathrm{C}$ for No. 248 and $265^{\circ} \mathrm{C}$ for No. 217. PL measurements were performed at $2 \mathrm{~K}$, excited by the $\mathrm{Ar}^{+}-514.5 \mathrm{~nm}$ line with $4.3 \mathrm{~mW}$ focused at $200 \mu \mathrm{m}$ spot, and detected by a PL system with a $0.75 \mathrm{~m}$ spectrometer, a cooled GaAs cathode photomultiplier and a lock-in amplifier under computer control.

X-ray photoelectron spectroscopy (XPS) experiments were performed in a VG ESCALAB MkII using a $\mathrm{Mg} \mathrm{K}_{\alpha} \mathrm{X}$-ray source $(1253.6 \mathrm{eV}, 120 \mathrm{~W})$ at a constant analyzer pass energy of $20 \mathrm{eV}$. The SIMS depth profiles were taken in a VG SIMSLAB connected to the ESCALAB via a preparation chamber using a

\footnotetext{
* Corresponding author: e-mail: zcfeng@ee.cc.ntu.edu.tw, Phone: +886 23366 3543, Fax: +886 223677467
} 
$9 \mathrm{keV} 20 \mathrm{nA} \mathrm{Ar}{ }^{+}$beam produced from a differentially pumped VG DP50B douplasmatron ion gun, detected by a VG MM12-12 quadrupole mass spectrometer $(0-800 \mathrm{amu})$.

\section{Results}

\subsection{Low-temperature photoluminescence}

Figure 1 shows $2 \mathrm{~K}$ PL spectra of (a) the $T_{\mathrm{s}}=200{ }^{\circ} \mathrm{C}$ sample (No. 248) and (b) the $T_{\mathrm{s}}=265^{\circ} \mathrm{C}$ one (No. 217). The former shows the free exciton transition $\mathrm{X}_{n=1}$ at $1.596 \mathrm{eV}$, the upper branch of free exciton-polariton $\mathrm{X}_{\mathrm{UP}}$ at $1.599 \mathrm{eV}$, the acceptor bound exciton $\mathrm{A}_{\alpha}$ at $1.591 \mathrm{eV}$ with its one longitudinal optical (LO) replica $\mathrm{A}_{\alpha}-1 \mathrm{LO}$, a donor-acceptor-pair (DAP) transition $\mathrm{P}$ at $1.548 \mathrm{eV}$ with its $1 \mathrm{LO}$ phonon replica $\mathrm{P}_{1}$, and deep level recombination bands of $\mathrm{B}$ at $1.499 \mathrm{eV}$ and $\mathrm{C}$ at $1.495 \mathrm{eV}$ as well as their corresponding phonon replicas, $\mathrm{B}_{1}, \mathrm{~B}_{2}, \mathrm{~B}_{3}, \mathrm{C}_{1}$, and $\mathrm{C}_{2}$ [18]. The latter with higher $T_{\mathrm{s}}$ exhibits PL spectra with only $\mathrm{A}_{\alpha}$ similar to the sample with lower $T_{\mathrm{s}}$. and more defects-related features, such as $\mathrm{D}_{\mu}$ at $1.593 \mathrm{eV}$ which is associated with donor-like structural defects or impurity-defect complexes, $\mathrm{E}$ and $\mathrm{F}$ bands which were assigned to excitons bound to acceptor-like structural defects or defect-impurity complexes, and defect-related $1.44 \mathrm{eV}$ broadband $[1,17]$.

\subsection{Secondary ion mass spectrometry (SIMS)}

Figure 2 displays the comparative SIMS depth profiles of these two samples. The $\mathrm{In}^{+}$profiles show that the In concentration in the entire CdTe layer is higher for the $T_{\mathrm{s}}=265{ }^{\circ} \mathrm{C}$ sample than that for the $T_{\mathrm{s}}=200{ }^{\circ} \mathrm{C}$ sample, even at the surface. Furthermore, the $\mathrm{In}^{+}$profile is consistent with In diffusing outwards from the InSb substrate and accumulating at the CdTe surface. Other $\mathrm{Cd}^{+}, \mathrm{Te}^{+}$and $\mathrm{Sb}^{+}$profiles are quite similar from two samples with only $\mathrm{Sb}^{+}$shown in Fig. 2, for a comparison with $\mathrm{In}^{+}$.

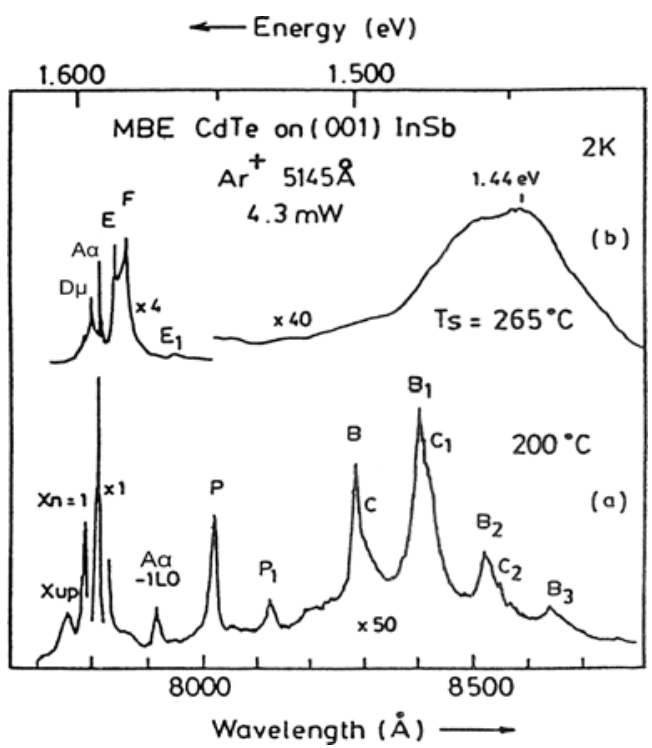

Fig. $12 \mathrm{~K}$ PL spectra of MBE-grown $\mathrm{CdTe} / \mathrm{InSb}$ with (a) $T_{\mathrm{s}}=200{ }^{\circ} \mathrm{C}$ (No. 248) and (b) $T_{\mathrm{s}}=265^{\circ} \mathrm{C}$ (No. 217).

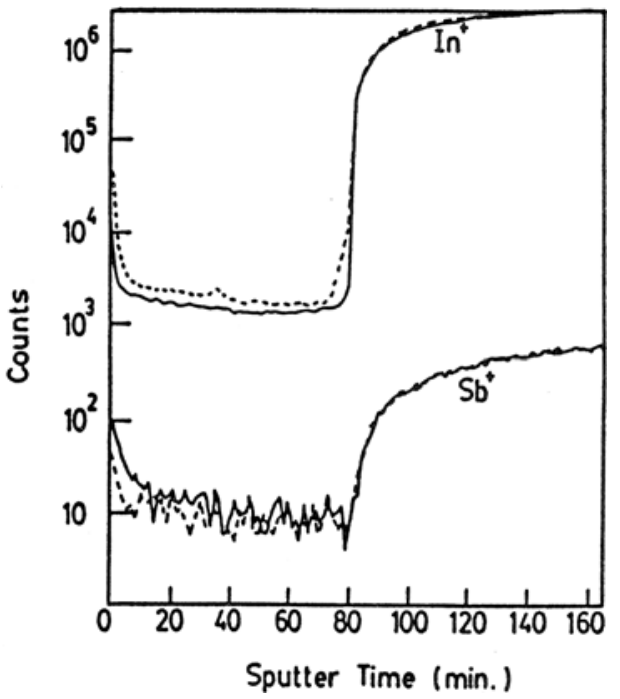

Fig. 2 SIMS depth profiles showing $\operatorname{In}^{+}$and $\mathrm{Sb}^{+}$signals of MBE-grown $\mathrm{CdTe} / \mathrm{InSb}$ heterostructures at $T_{\mathrm{s}}=200{ }^{\circ} \mathrm{C}$ (solid lines) and $T_{\mathrm{s}}=265^{\circ} \mathrm{C}$ (dashed lines). 


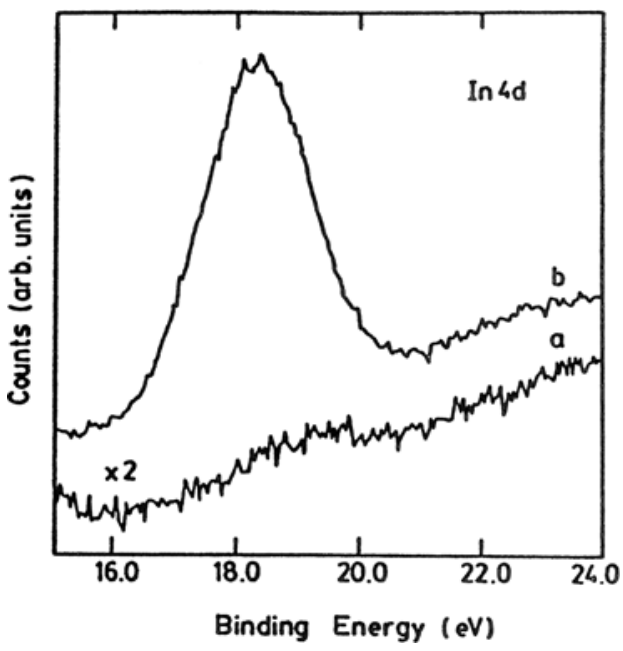

Fig. 3 XPS In 4d signals, as-received, of MBE-grown CdTe/InSb at (a) $T_{\mathrm{s}}=200{ }^{\circ} \mathrm{C}$ and (b) $T_{\mathrm{s}}=265^{\circ} \mathrm{C}$.

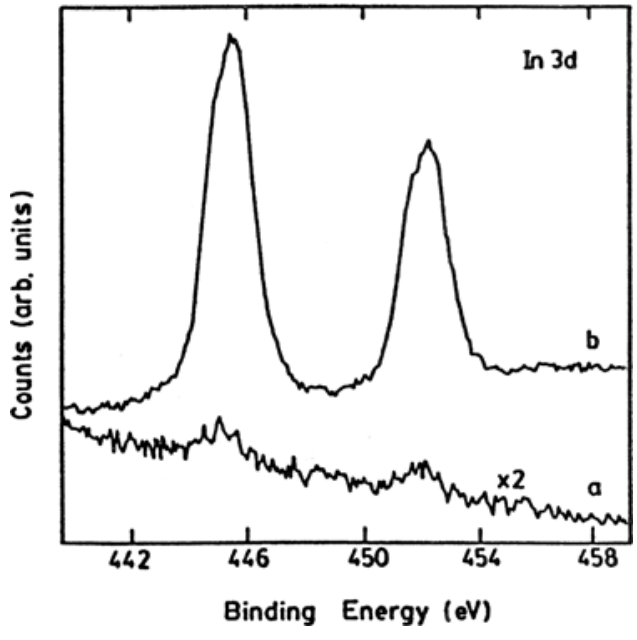

Fig. 4 XPS In3d signals, after light $\mathrm{Ar}^{+}$sputtering, of MBE-grown CdTe/InSb at (a) $T_{\mathrm{s}}=200{ }^{\circ} \mathrm{C}$ and (b) $T_{\mathrm{s}}=265^{\circ} \mathrm{C}$.

\subsection{X-ray photoelectron spectroscopy (XPS)}

Figure 3 shows the comparative XPS In $4 d$ energy spectra, for these two as-received samples, while Fig. 4 shows their XPS In $3 \mathrm{~d}$ spectra after light $\mathrm{Ar}^{+}$sputtering to remove any surface contaminants. Strong In signals appear from the $T_{\mathrm{s}}=265^{\circ} \mathrm{C}$ sample in both figures while the signals are significantly weaker for $T_{\mathrm{s}}=200^{\circ} \mathrm{C}$ sample. Note that XPS probes only the surface region to a depth of about $5 \mathrm{~nm}$. Since the as-received and sputtered In $4 \mathrm{~d}$ and $3 \mathrm{~d}$ XPS spectra are virtually unchanged for both samples, we conclude that these In signals are not due to subsequent surface contamination.

\section{Discussion}

From the present study, the following observations are obtained:

(1) The surface analytical techniques reveal In interdiffusion directly. The SIMS depth profile and the XPS In $3 \mathrm{~d}$ and $4 \mathrm{~d}$ spectra indicate that the In concentration in the CdTe film grown at high $T_{\mathrm{s}}$ is significantly higher than that at low $T_{\mathrm{s}}$, and this can be attributed to indium interdiffusion from the InSb substrate. Higher substrate growth temperatures enhances In interdiffusion across the $\mathrm{CdTe} / \mathrm{InSb}$ interface, leading to a higher indium concentration in the $T_{\mathrm{s}}=265^{\circ} \mathrm{C}$ sample.

(2) PL spectra from the two $T_{\mathrm{s}}$ samples are quite different. The low $T_{\mathrm{s}}$ sample possesses strong free and acceptor-bound excitons, and relatively weaker and sharper emissions in the deep level range of $1.4-1.5 \mathrm{eV}$, characteristic of high quality single crystalline CdTe [18]. The high $T_{\mathrm{s}}$ sample has a dull FE feature only, a stronger donor-bound exciton like feature associated with structural defects, strong defectrelated $\mathrm{E}$ and $\mathrm{F}$ lines and a deep $1.44 \mathrm{eV}$ broad band [18]. Previous TEM observations had shown that high $T_{\mathrm{s}}$ CdTe films contain a high density of dislocations [17]. The above PL features from the high $T_{\mathrm{s}}$ CdTe film have been associated with structural defects or impurity-defect complexes $[17,18]$. The present study shows that the impurity involved in these complexes should be mainly indium.

CdTe is well lattice matched with InSb. The lattice constant for CdTe, $a(\mathrm{CdTe})$, is $0.6486 \mathrm{~nm}$ or $0.6482 \mathrm{~nm}$ at room temperature (RT) [14]. The $a(\mathrm{InSb})$ lattice constant is $0.6479 \mathrm{~nm}$ [18]. The difference between them is $0.1 \%$ or $0.04 \%$ with the lattice constant of $a(\mathrm{CdTe})$ being slightly higher than that of $a(\mathrm{InSb})$. The linear thermal expansion coefficient $\alpha$ of InSb is about $5.5 \times 10^{-6} / \mathrm{K}$ between $10^{\circ} \mathrm{C}$ and $60{ }^{\circ} \mathrm{C}$, while $\alpha(\mathrm{CdTe})=(4.70-4.90) \times 10^{-6} / \mathrm{K}$ at $283 \mathrm{~K}$ which is lower than the value of $\alpha(\mathrm{InSb})$. 
We had previously varied $T_{\mathrm{s}}$ between $170{ }^{\circ} \mathrm{C}$ and $285^{\circ} \mathrm{C}$ and obtained an optimum $T_{\mathrm{s}}$ of $185^{\circ} \mathrm{C}$. The CdTe films grown at this $T_{\mathrm{s}}$ and below $200^{\circ} \mathrm{C}$ show high crystalline perfection [18]. Indeed, PL and structural features of CdTe films grown under $185-200{ }^{\circ} \mathrm{C}$ are quite similar. Growth at higher $T_{\mathrm{s}}$ within this range is better to avoid the Te-droplets. Their cross-sectional TEM (XTEM) images across the $\mathrm{CdTe} / \mathrm{InSb}$ interface are very clean and without obvious dislocations. However, the $\mathrm{CdTe} / \mathrm{InSb}$ interface of $T_{\mathrm{s}}>250^{\circ} \mathrm{C}$ samples were filled with numerous dislocations, stacking faults and micro-cracks, the density of which increased with increasing $T_{\mathrm{s}}$ between $225^{\circ} \mathrm{C}$ and $285{ }^{\circ} \mathrm{C}$.

To explain the above features, we may assume that there would exist an exact lattice match between $\mathrm{CdTe}$ and $\mathrm{InSb}$ at $185^{\circ} \mathrm{C}$ (or below $200^{\circ} \mathrm{C}$ ) and that $a(\mathrm{CdTe})>a(\mathrm{InSb})$ as $T_{\mathrm{s}}<185^{\circ} \mathrm{C}$ and $a(\mathrm{CdTe})<a(\mathrm{InSb})$ as $T_{\mathrm{s}}>185^{\circ} \mathrm{C}$ or $200^{\circ} \mathrm{C}$. This difference in lattice constants increases beyond $225^{\circ} \mathrm{C}$. As we grow $\mathrm{CdTe}$ on $\mathrm{InSb}$ at a higher $T_{\mathrm{s}}$, the larger lattice mismatch would lead to dislocation lines into $\mathrm{CdTe}$ and the development of these dislocation lines. A large amount of In leads to the strong signals in the XPS spectra and SIMS profiles, and also to the strong In- and defect-related PL emissions from the top CdTe layers.

\section{Conclusion}

In conclusion, the interface properties of $\mathrm{CdTe} / \mathrm{InSb}$ grown by molecular beam epitaxy (MBE) and the In interdiffusion were studied by optical and surface techniques of photoluminescence (PL), X-ray Photoelectron Spectroscopy (XPS) and Secondary Ion Mass Spectrometry (SIMS). The In interdiffusion has been revealed directly by SIMS depth profile and XPS In 3d and 4d spectra, indicating that the In concentration in CdTe film grown with high substrate growth temperature $T_{\mathrm{s}}$ is much higher than that with low $T_{\mathrm{s}}$. Higher $T_{\mathrm{s}}$ enhanced the In interdiffusion across the $\mathrm{CdTe} / \mathrm{InSb}$ interface, leading to more indiums detected. These are correlated to the PL spectra from two $T_{\mathrm{s}}$ samples which are quite different. The low $T_{\mathrm{s}}$ one possesses strong free and acceptor-bound excitons, relatively weaker and sharp emissions in the deep level range of $1.4-1.5 \mathrm{eV}$, characteristic of high quality of single crystalline CdTe. The high $T_{\mathrm{s}}$ one has dull FE feature only and strong defect-related $\mathrm{E}$ and $\mathrm{F}$ lines and deep $1.44 \mathrm{eV}$ broad band. It predicts that there would exist an exact lattice match between $\mathrm{CdTe}$ and $\mathrm{InSb}$ at the optimum $T_{\mathrm{s}}$ of $185^{\circ} \mathrm{C}$ and that $a(\mathrm{CdTe})>a(\mathrm{InSb})$ as $T<185^{\circ} \mathrm{C}$ and $a(\mathrm{CdTe})<a(\mathrm{InSb})$ as $T>185$ or $200{ }^{\circ} \mathrm{C}$. At higher $T_{\mathrm{s}}$, the bigger lattice mismatch would lead to dislocations and In will diffuse more efficiently along these dislocation lines from InSb substrate into CdTe layer. The big amount of In leads to the strong signals of XPS spectra and SIMS profiles, and also to the strong In- and defect-related PL features. Optimizing $T_{\mathrm{s}}$ and other growth conditions are efficient to depress the In interdiffusion during the II-VI/III-V growth.

Acknowledgements We would like to thank Profs. W. J. Choyke and R. F. C. Farrow for help in this work. The work at National Taiwan University was supported by funds from National Science Council of Republic of China, NSC 93-2218-E-002-011, 93-2215-E-002-035 and 94-2215-E-002-019.

\section{References}

[1] C. R. Corwine, J. R. Sites, T. A. Gessert, W. K. Metzger, P. Dippo, Jingbo Li, A. Duda, and G. Teeter, Appl. Phys. Lett. 86, 221909 (2005).

[2] D. Shvydka, J. P. Rakotoniaina, and O. Breitenstein, Appl. Phys. Lett. 84, 729 (2004).

[3] Y. Yan, M. M. Al-Jassim, and K. M. Jones, J. Appl. Phys. 94, 2976 (2003).

[4] M. J. Romero, D. S. Albin, M. M. Al-Jassim, X. Wu, H. R. Moutinho, and R. G. Dhere, Appl. Phys. Lett. 81, $2962(2002)$.

[5] M. J. Soares, M. C. do Carmo, Proc. SPIE 4469, 57 (2001).

[6] J. Huerta-Ruelas, M. Lopez-Lopez, and O. Zelaya-Angel, Jpn. J. Appl. Phys. 39, 1701 (2000).

[7] Y.-H. Kim, S.-Y. An, J.-Y. Lee, I. Kim, K.-N. Oh, S.-U. Kim, M.-J. Park, and T.-S. Lee, J. Appl. Phys. 85, 7370 (1999)

[8] C. Heske, U. Winkler, H. Neureiter, M. Sokolowski, R. Fink, E. Umbach, Ch. Jung, and P. R. Bressler, Appl. Phys. Lett. 70, 1022 (1997). 
[9] Z. C. Feng, H. Gong, W. J. Choyke, N. J. Doyle, and R. F. C. Farrow, J. Mater. Sci., Mater. Electron. 7, 23 (1996).

[10] D. Drew, J. Sahm, W. Richter, and D. R. T. Zahn, J. Appl. Phys. 78, 4060 (1995).

[11] A. T. S. Wee, Z. C. Feng, H. H. Hgn, K. L. Tan, R. F. C. Farrow, and W. J. Choyke, J. Phys.: Condens. Matter 7, 4359 (1995).

[12] S. Tatarenko, F. Bassani, J. C. Klein, K. Saminadayar, J. Cibert, and V. H. Etgens, J. Vac. Sci. Technol. A 12(1), 140 (1994).

[13] M. S. Boley, R. J. Thomas, M. Chandrasekhar, H. R. Chandrasekhar, A. K. Ramdas, M. Kobayashi, and R. L. Gunshor, J. Appl. Phys. 74, 4136 (1993).

[14] T. W. Kim, M. Jung, H. L. Park, H. K. Na, and J. S. Kim, Appl. Phys. Lett. 61, 1101 (1992).

[15] N. C. Giles, K. A. Bowers, R. L. Harper, Jr., S. Hwang, and J. F. Schetzina, J. Cryst. Growth 101, 67 (1990).

[16] Z. C. Feng, S. Perkowitz, J. M. Wrobel, and J. J. Dubowski, Phys. Rev. B 39, 12997 (1989).

[17] Z. C. Feng, M. G. Burke, and W. J. Choyke, Appl. Phys. Lett. 53, 128 (1988).

[18] Z. C. Feng, A. Mascarenhas, and W. J. Choyke, J. Lumin. 35, 329 (1986). 